\title{
Mar y Mundo en el imaginario desiderativo de Melibea
}

\author{
Víctor Calderón de la Barca Fernández \\ Universidad de Kanagawa
}

\section{Introducción}

En el auto XVI de la Tragicomedia Melibea expresa en un largo parlamento su vehemente deseo de rendirse al «ilícito amor» de Calisto y someterse a su voluntad contrariando los proyectos matrimoniales de sus padres. Entre las arrebatadas palabras que Melibea pronuncia se hallan los sintagmas "rodear el mundo", "pasar la mar»y "venderme en tierra de enemigos".

El objetivo de este artículo es analizar estos sintagmas y desentrañar su sentido partiendo de la hipótesis de una lectura que, desbordando los límites de su formulismo retórico, tome como referentes los decisivos acontecimientos que estaban teniendo lugar en las mismas fechas en que aparecen las primeras impresiones de La Celestina y estaban cambiando la imagen del mundo en Castilla y, por extensión, en Europa. El bachiller en Leyes Fernando de Rojas difícilmente pudo permanecer ajeno a la difusión de las noticias del "Descubrimiento" y de los sucesivos viajes colombinos.

En este contexto se propone, siempre con carácter conjetural, ya que no hay pruebas ecdóticas, aunque tampoco pruebas en contrario, que los sintagmas tuviesen como referentes no el Mediterráneo, sino el Atlántico, y una posible circunnavegación del globo terráqueo teóricamente demostrada, aunque aún no realizada.

Para el análisis se traen a colación y se contrastan distintos testimonios de la tradición literaria española en que aparecen dichos sintagmas y algunas de las traducciones de La Celestina que, a mi juicio, problematizan la interpretación e impiden darla por cerrada. 


\section{Carácter político de una ubicación literaria}

En el planto del último auto de La Celestina en el que Pleberio exhala su queja contra la variable fortuna, el mundo y el amor, el desconsolado padre que acaba de presenciar el suicidio de Melibea se pregunta retóricamente:

¡O duro coraçón de padre! ¿Cómo no te quiebras de dolor, que ya quedas sin tu amada heredera? ¿Para quién edifiqué torres? ¿Para quién adquirí honrras? ¿Para quién planté árbores? ¿Para quién fabriqué navíos? (Russell LC: 609) $)^{1}$.

Esta alusión a las torres, a los árboles y a los navíos en este lamento, como las que diseminadas a lo largo del texto dibujan el paisaje urbano de La Celestina, han dado pie a la especulación de cuál fuera la ciudad en que se desarrolla la acción de la obra de Fernando de Rojas: Salamanca, Toledo, Sevilla...2

Si, como recuerda Gómez Moreno (2009: 214), navío es término propio de un "bajel grande de alto borde», tal como lo define el Tesoro de Covarrubias y otros testimonios anteriores, habría que descartar aquellas ciudades, como Toledo o Salamanca, que no son puertos, ni siquiera fluviales. Sin embargo, entre los primeros defensores de la ubicación salmantina —o al menos de la patria salmantina de Calisto- contamos con uno de los primeros traductores de la obra de Rojas al francés. En efecto, Jacques de Lavardin, en el "Argument de la Tragicomedie", caracterizaba a Calisto como «extraict de noble et ancienne famille de Salemanques ${ }^{3}$.

1.- Las citas de La Celestina las he tomado de la $3^{a}$ edición de Peter E. Russell, col. Clásicos Castalia, Madrid, Castalia, 2001. Las citas de La Celestina siguiendo la edición señalada aparecerán con la referencia $L C$, seguida del número de página. La transcripción de Russell de las frases y el pasaje analizados en este artículo apenas difiere del texto de la edición de Francisco J. Lobera et al., col. Biblioteca Clásica, dir.Francisco Rico, Barcelona, Crítica, 2000, que es edición de la Tragicomedia en veintiún actos para cuya fijación se tomaron en cuenta todos los testimonios primitivos hasta el año 1520, y que también he consultado. He tenido también a la vista el facsímil de la edición de Valencia, Juan Joffre, 1514. -- 70 hoj. ; 4 . Espasa-Calpe, Madrid, 1975. La reproducción digital de la Biblioteca Nacional (España), sig. R/4870, puede verse en la Biblioteca Virtual Miguel de Cervantes (<http://www.cervantesvirtual.com/nd/ark:/59851/ bmcnk390>). También he consultado la edición paleográfica de Nicasio Salvador Miguel y Santiago López-Ríos publicada por la Institució Alfons el Magnànim, Valencia, 1999.

2.- Las distintas posturas sobre su localización quedan recogidas en Ángel Gómez Moreno, "La torre de Pleberio y la ciudad de La Celestina», en El mundo social y cultural de La Celestina, eds. Ignacio Arellano y Jesús M.Usunáriz, Madrid, Iberoamericana, 2009 (pp. 211-236). A las polémicas sobre la localización de la ciudad dedicó María Rosa Lida de Malkiel una larga nota bibliográfica a pie de página de su La originalidad artística de La Celestina, Buenos Aires, Eudeba, 1962, p. 163.

3.- La información bibliográfica de las traducciones utilizadas aparece, tras la Bibliografía citada, bajo el epígrafe Traducciones. Las traducciones consultadas han sido la italiana de 
Con todo, en el mismo artículo de Gómez Moreno se defiende la tesis de la indeterminación deliberada de la ubicación de La Celestina en la línea iniciada por Lida de Malkiel y seguida por Maravall. Vale la pena reproducir, aunque solo sea parcialmente, la paráfrasis que Maravall (1964: 62) hizo de la observación de Lida de Malkiel: «...no se trata de ninguna ciudad en concreto, sino de una ciudad inventada, recompuesta imaginativamente por el autor, siguiendo probablemente el modelo de esas ciudades de ficción que eran frecuentes en la pintura flamenco-ca tellana de la época».

A los numerosos ejemplos de las artes plásticas con que Lida de Malkiel en su libro (1962: 164 n. 7) y Gómez Moreno en su artículo ilustran estas palabras podrían agregarse otros. Baste aquí uno que, aunque italiano y anterior, está considerado como prototipo del paisaje urbano en la pintura del prerrenacimiento, el fresco conocido como Ciudad junto al mar del maestro Ambrosio Lorenzetti, que se conserva en la pinacoteca de Siena -escenario de la Historia de duobus amantibus de Eneas Silvio Piccolomini ${ }^{4}$-, donde aparecen muchos de los elementos arquitectónicos y paisajísticos mencionados en La Celestina. La ciudad mercantil, la de los burgos y los gremios, abre sus plazas y calles, levanta sus lonjas, palacios y casas, sus torres, iglesias y campanarios así en Flandes o Italia como en Castilla, Aragón o Portugal. El modelo de representación es el mismo y, sin embargo, "la originalidad artística de La Celestina» parece pedir una ocupación distinta del espacio, como si huyendo de la tipología heredada, fuesen los personajes los que lo creasen a través de sus peripecias: «Estos escenarios no preexisten, por así decirlo, a la acción..., antes bien... surgen a medida que la acción los requiere y, en muchos casos, complementan sutilmente el carácter y situación de los personajes» (Lida de Malkiel 1962: 150).

La ciudad, como representación socio-dramática, encierra en sus muros unas vidas que parecen querer derribarlos. La tragedia sobreviene y se enseñorea de la obra cuando los derribados no son los muros, que permanecen ejemplarmente erectos, sino las vidas.

En su monumental estudio de La Celestina Lida de Malkiel, tras rastrear los antecedentes literarios más o menos próximos o lejanos de la «terenciana obra", se detiene en el análisis de los personajes. La conclusión con que finaliza el estudio de cada uno de ellos es invariablemente la misma y coincide con la valoración global de la obra: «lo que la Tragicomedia ofrece

Ordóñez, las francesas de Lavardin y Lavigne y la inglesa de Mabbe. Los subrayados de los pasajes traducidos son míos.

4.- Aunque en la Historia propiamente dicha no aparece el nombre de la ciudad, su localización en Siena consta en la Carta a Mariano Sozzini que precede al texto: «...no escucharás los amores de Troya ni los de Babilonia, sino los de nuestra ciudad, aunque uno de los amantes nació en el norte de Europa» (Piccolomini 2006:112). 
no es un conflicto abstracto de categorías abstractas, sino criaturas individuales enzarzadas en una heraclitea contienda de egoísmos» (1962: 728).

La ciudad de Celestina, Calisto y Melibea es, desde luego, una ciudad literaria, su ubicación exacta es indemostrable y hasta innecesaria, como lo sería la de la lorquiana casa de Bernarda Alba, que lo mismo podría estar en un pueblo andaluz que en otro de la vieja Castilla, pero la singularidad de los caracteres de La Celestina se proyecta sobre la ciudad misma que habitan hasta sobreponerse al común esquematismo de las ciudades de ficción de las pinturas y aquilatarse en una que no puede ser sino castellana. "La ciudad en que se desarrolla La Celestina - concluye Lida de Malkiel (1962: 167) — es la imagen genérica de la ciudad española de sus tiempos, con rasgos comunes a las más y sin peculiaridades de ninguna».

La conclusión de la erudita argentina, de la que difícilmente se puede disentir, no deja de subrayar - acotándolos- los límites de tal generalización. Lo que de universal pueda tener o haber tenido La Celestina ha de entenderse, por tanto, no como algo común al género humano y que pueda ser igualmente compartido, sino desde la plataforma sociohistórica en que fue engendrada: una ciudad del reino de Castilla en tiempos de los Reyes Católicos, reino cuyas ciudades reciben el influjo humanista ${ }^{5}$, pero que acaba de salir de una larga guerra contra los moros de Granada, ha conocido la expulsión de los judíos y empieza a mirar a Oriente desde las playas atlánticas.

Para la temprana y gran difusión de La Celestina mediante traducciones y adaptaciones pueden ofrecerse varias explicaciones, entre ellas, el favor del público o el gusto literario de la época, ligados al uso de la imprenta y los intereses comerciales de los libreros, o el influjo cultural de la Italia renacentista, desde donde se propaga la obra de Rojas por toda Europa a partir de la traducción italiana de Ordóñez ${ }^{6}$. Pero no debería subestimarse la influencia de la propia España sobre Italia justo cuando los reinos reunidos en las coronas de Isabel y Fernando —el príncipe elogiado por Maquiavelo- comienzan a desbordar sus límites geográfico para cumplir un proyecto de imperio universal con la complicidad de un Papa nacido en Valencia.

5.- Influjo que es preciso matizar en la línea defendida por Monsalvo Antón (2011: 47): "Los humanistas italianos del xv escriben y trabajan en la lengua latina... En cambio, una monarquía como la castellana, aunque admitiera y apreciara la tradición clásica y humanista, al incorporarla desprovista de su idioma original, desvirtuaba dicha tradición y robustecía la lengua vernácula. Hay que ver desde esta óptica propia la recepción de la cultura italiana en la Castilla del XV».

6.- Ottavio Di Camillo subraya que «la recepción de la obra en Italia desde los primeros años del siglo XVI cobra un valor excepcional, porque no sólo se da casi simultáneamente a la de Castilla, sino que la versión italiana termina sustituyendo el original castellano en su primera difusión europea» (2012: 216-226). Cita extraida de PDF < http://www.academia. edu/2332985/> p. 6. vid. Bibliografía citada. 


\section{Un jardín junto al mar}

Que Pleberio fabrique naves le adscribe, si no a la aristocracia, al menos a la pujante burguesía mercantil de la época. Melibea, hija de un rico naviero, se solaza o cura de su melancolía subiendo «al açotea alta, por que desde allí goze de la deleytosa vista de los navíos» (LC: 593).

A pesar de que no pueda presentarse como prueba lo que solo puede ser objeto de conjetura ${ }^{7}$, cabría, en defensa de la ubicación de la casa y huerto de Pleberio en una ciudad con puerto de mar, traer a colación dos testimonios. Uno, bien que muy posterior al de obra de Fernando de Rojas, aparece en la Segunda Celestina, de Feliciano de Silva, de 1534. La Celestina "resucitada», haciendo ahora de tercera entre Polandria y Felides, le dice a este: "...que tú vayas esta noche allá a la una, y por un escala puedes entrar a la parte que la mar bate en el jardín, y él está tan apartado que, sin que se pueda oír, puedes cabe las rejas de dentro hazer las señas tañendo y cantando» (Silva 1988: 412-13). Esta precaución quizá pueda explicar a posteriori la despreocupación del Calisto de Rojas en su entrevista con Melibea. A la ubicación junto al mar de este jardín de Polandria se hacen dos o tres referencias más: «... pone aquí el escala cabe la mar» —ordena Felides a su criado (427). Más adelante Polandria alaba la voz de su enamorado, que le llega "con el son del ruido de las ondas del mar y el regozijo delicado de los aires de los cipreses» (438), y en la noche en que se consuma el matrimonio secreto de los amantes se recrea «debaxo de las sombras de estos cipreses, a los frescos aires que vienen regozijando las aguas marinas por encima de los poderosos mares» (565).

En La Tercera Celestina, de 1542, sin embargo, Sancho de Muñón situaría su Tragicomedia de Lisandro y Roselia en Salamanca: "Ya sabes que en Salamanca —apostilla Elicia, la nueva Celestina - pocas hermosas hay» (1977: 61).

El segundo testimonio que permite tentativamente - siempre más como indicio que como prueba - ubicar la casa de Melibea en una ciudad portuaria procede de un pasaje de la obra del propio Rojas. En el decimosesto auto de la Tragicomedia de Calisto y Melibea, es decir, uno de los añadidos a la Comedia, Melibea, avisada de su criada Lucrecia, oye a escondidas el propósito que sus padres tienen de casarla. No pudiéndolo sufrir da rienda suelta a su enojo en un largo parlamento en el que anuncia su determinación de gozar del amor de Calisto bien fuera del matrimonio que sus padres traman. Las arrebatadas palabras de Melibea manifiestan su ya completa entrega al «ilícito amor» de Calisto. Así la oímos decir:

7.- Russell en su edición de La Celestina alude a los comentarios que sobre la localización de la acción de la obra ha suscitado esta frase concluyendo que no hay sugerencias suficientes para situarla en Sevilla u otro puerto de mar (p. 593, nota 12 del Acto XX). 
Haga y ordene de mí a su voluntad. Si passar quisiere la mar, con él yré; si rodear el mundo lléveme consigo; si venderme en tierra de enemigos, no rehuyré su querer $(L C: 547)^{8}$.

Seguramente esta referencia a «la mar», por muy explícita que sea, no es suficiente para ubicar la ciudad de Pleberio en alguno de los puertos comerciales de los que salían la lana, el hierro, el vino o el trigo del reino de Castilla, pero al menos permite conjeturar que la idea del mar sobrepasa el mero procedimiento retórico para inscribirse en el imaginario desiderativo de una Melibea dispuesta a una fuga perentoria.

La estructura retórica del pasaje — valga de analogía el meridiano que atraviesa tres paralelos de distinta amplitud- puede adscribirse a la variante de la amplificatio que denominamos "enumeración", pero en un sentido ascendente, climático, que también podría entenderse como "gradación». Con su obvio paralelismo sintáctico cada frase repite la idea nuclear que encabeza el pasaje — «Haga y ordene de mí a su voluntad»—, pero la repetición no se ilustra con una mera acumulación caótica de elementos desordenados o caprichosamente traídos ni se limita a reiterar el deseo expresado al principio. Antes al contrario, hay un orden constituido por la elección deliberada de tres elementos distintos, cada uno de los cuales plantea un problema que se ha de intentar resolver desde una perspectiva historicista o, si se prefiere, política. La retórica no es aquí mero adorno.

Ello obliga a analizar las 3 oraciones o elementos de la amplificació como posibles signos referenciales de una realidad históricamente determinada y vivida por el autor de la obra, de modo que las fuentes literarias de las que tan abundantemente bebió - petrarquistas sobre todo- han de ser vistas como los útiles con que construyó un artefacto literario que, como ya queda dicho, es netamente castellano o español. $\bigcirc$, dicho de otra manera, que el análisis se incribe en la convicción de que La Celestina no debe entenderse como "obra de valor universal», sino que hay que interpretarla desde la plataforma del incipiente imperio que se estaba forjando en los alrededores de 1492.

8.- En el ejemplar de la edición Plantiniana de 1595 de CELESTINA. Tragicomedia DE CALISTO Y MELIBEA de la BNE (Signatura Cerv.Sedó / 8645, p.298) se intercala el verbo «quisiere» entre "si venderme» $\mathrm{y}$ "en tierra de enemigos». La observación puede tener su interés a la hora de valorar la fidelidad de una edición al arquetipo de Rojas. En el texto reconstruido de las ediciones modernas que he seguido, las de Russell en Castalia y de Rico en Crítica, así como en la de Criado de Val (1984: 257,258 / Signatura del ejemplar de BNE: 4/218027) el verbo no aparece. 


\section{Traduttore, ¿traditore?}

Se ofrecen aquí, para su contraste y comentario, cuatro traducciones del pasaje del auto XVI arriba citado (LC: 547): la italiana de Ordóñez, las francesas de Lavardin y Lavigne - elegidas la primera por su mayor proximidad al original y la segunda como interpretación moderna- y la inglesa de Mabbe. Las traducciones problematizan la interpretación, por cuanto no solo difieren entre sí, sino que en algún aspecto parecen alejarse, siquiera parcialmente, del original español. Además, para juzgar las traducciones, no puede tomarse como criterio de verdad el original español mientras no se le pueda dar un sentido unívoco, que no puede ser sino el que le diera su autor, asunto hermenéutico, a mi juicio, aun no resuelto. Si el análisis intertextual -interno-, se demuestra insuficiente, habrá de recurrirse a los referentes externos, sociohistóricos en este caso, de la época y el lugar de gestación y publicación de la obra.

En la Tragicocomedia di Calisto e Melibea nouamente traducta de spagnolo in italiano idioma por Alfonso de Ordóñez e impresa en Roma en 1506 por Eucharium Silber leemos:

lo I amore non admitte: $\int a l u o$ uero amore impagamen | to:Solo apenfare in lui me reallegro:auederlo/ godo: | uedendolo me glorifico I con e fJo uoglio andare:faclcia

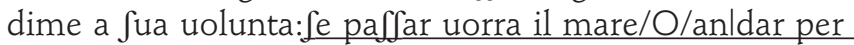
tutto il mondo menime eeco:che mai lo ha I bandonaro: $\mathrm{i}$

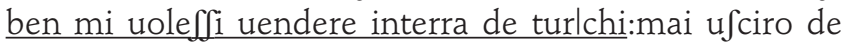
fua uolunta las ime mio patre goldere lui I fe loro uogliono godere dime?.

En 1527 aparece en París una primera traducción francesa de La Celestina, que en realidad se hace a partir de la italiana de Ordóñez. En la de 1578 de Jacques de Lavardin, que copiamos de la edición de Drysdall (1974: 222), el pasaje se vierte así:

Amour ne se paye, que de vray amour. Seulement à penser en luy, ie suis en liesse, le voiant ie me resiouis, le voyant ie me gloriffie. Auec luy ie veux aller, face de moy à son plaisir, veut-il passer la mer, ie le suiuray, veut il tournoyer la terre, me meine quant et luy, iamais ne l'abandonneray, et me deust il vendre pour esclaue au pays des Turs: rien ne me departira de ses commande-

9.- De la traducción italiana de Ordóñez se conservan distintas ediciones. Me he limitado a la consulta de la más primitiva, es decir, la de Roma de 1506, que se puede encontrar en la Biblioteca Nacional Marciana de Venecia. La transcripción del fragmento la copio de Giraldo (2013). En la versión no estrictamente paleográfica de Kathleen V. Kish la lectura del fragmento es la misma (1973: 224). 
mens. Que mon pere me souffre iouyr de luy, s'il veut iouyr de ma vie ${ }^{10}$.

En la traducción francesa de Lavigne (1873: 204, 205), impresa en París, el pasaje queda de la siguiente manera:
À penser à lui, je me réjouis ; à le voir, je ressens du bonheur ; à l'entendre, je me glorifie. Qu'il fasse et qu'il ordonne de moi à sa fantaisie. S'il veut traverser les $\underline{\text { mers, }}$ j'irai avec lui ; s'il veut parcourir le monde, qu'il m'emmène; s'il veut me vendre sur une terre d'ennemis, je ne résisterai pas à sa volonté. Que mes parents me laissent jouir de lui, s'ils veulent jouir de moi ;

Es muy probable que algunas copias de La Celestina llegaran a Inglaterra en las mismas naves que llevaban a Catalina de Aragón para su desposorio con el Príncipe de Gales. La primera traducción al inglés es una versión en verso de Rastell -impresor y tal vez también autor de la misma - de hacia 1530 de solo algunas partes del Prólogo y los seis primeros autos, y con un "happy ending» que se desvía completamente del original de Rojas. El verdadero éxito de La Celestina en Inglaterra llegaría con la traducción de James Mabbe, dada a la imprenta en 1631, aunque de hecho la tradujera muchos años antes. Se conserva una versión abreviada de la Tragicomedia en el denominado manuscrito de Alnwick, cuya redacción puede datarse entre 1603 y 1611. Mabbe -insigne hispanista y traductor del Guzmán de Alfarache - se sirvió para su excelente y original traducción de la Tragicomedia tanto de la italiana de Ordóñez como de la francesa de Lavardin (Botta 1992: 356), pero teniendo a la vista el texto original en español, probablemente un ejemplar de la edición Plantiniana de Antwerp de 1595 (Martínez Lacalle 1972: 33) o también el de la de 1599 (Botta 1992: 370). Del fragmento que nos atañe entresaco estas frases de la edición de Martínez Lacalle (1972: 245):

\section{Yf he will passe the seas, I will goe with him. Yf he will compase the world, I will accompanie him...}

A diferencia del manuscrito de Alnwick, la versión impresa publicada en 1631 con el título de The Spanish Bawd está muy revisada. Por lo que se refiere a este pasaje es más completa, sin omisiones, y la traducción difiere parcialmente (Mabbe 1631: $170{ }^{11}$ :

10.- Para su transcripción Drysdall utilizó la edición de Robinot. En el ejemplar de la BNE de la edición de Bonfons del mismo año de 1578 (Signatura R/41530) el texto es idéntico, a excepción de la palabra "Turs», que aparece como «Turcs».

11.- Ref. bibliográfica en la entrada dedicada a Mabbe del apéndice de Traducciones, tras Bibliografía. 
if he will goe to sea, I will goe with him; if hee will round the world, I will along with him; if he will sell mee for a slauve in the enemies Countrey, I will not resist his desire;

\section{Tierra de enemigos}

Si seguimos la traducción de Alfonso de Ordóñez — familiar del papa Julio II, según él mismo declara (Kish 1973: 31)_, esa «tierra de enemigos» donde Melibea podría ser vendida - como esclava - por Calisto sería "terra de turchi», como ya había advertido Russell en su edición de $\mathrm{La}$ Celestina (2001: 547 n. 22), aunque la especificación no está en las edici nes españolas del texto de Rojas. Se trata, por tanto, de una modificación del traductor ${ }^{12}$, similar, por cierto, a la que hace al traducir la sentencia que Rojas pone en labios de Celestina en el «sétimo auto» - "que mientra más moros, más ganancia» (LC: 391)—, que en la versión de Ordóñez queda como «che mentre piu inimici sonno, piu guadagno ce» (Kish 1973: 139). Si «tierra de enemigos» se traduce por «terra de turchi», ahora el procedimiento es inverso: se traduce «moros» como «inimici».

La traducción francesa de Jacques de Lavardin — gentilhombre de la casa del rey Enrique III-, aunque pueda haber tenido a la vista una edición española, sigue la italiana de Ordóñez, como puede comprobarse en este pasaje, en el que «uendere interra de turchi» se recoge traducido como "vendre pour esclaue au pays des Turs», con la adición, perfectamente señalada por Denis L. Drysdall, de las dos palabras que hemos puesto en cursiva, que no están ni en el texto español de Rojas ni en la traducción italiana de Ordóñez.

La frase original «si venderme en tierra de enemigos» sufrió, pues, en sus tempranas traducciones al italiano y al francés, sin que se vean muy bien las razones, una alteración de cierta importancia. En la inglesa de Mabbe transcrita por Martínez Lacalle la frase se omite y queda sin traducir, sin que se puedan aducir aquí tampoco razones claras. No pueden serlo, en este pasaje, ni la censura religiosa impuesta al teatro isabelino por el Act of Parliament de 1606 ni tampoco, a pesar de las libertades que Mabbe se tomó para adaptar la obra al inglés de sus contemporáneos, razones de estilo. Tal vez se trate solo de una omisión hecha para aligerar el texto pensando en una puesta en escena de la obra.

12.- Cabe la reserva de que el texto base que Ordóñez manejara fuese una temprana edición perdida de la Tragicomedia, anterior a las que se han conservado con fecha de 1502, ya fueran de ese año o posteriores. Ello convertiría a la traducción italiana en su más antiguo testimonio (Scoles 1961: 155-217; Kish 1973: 11). Sin embargo, mientras no se disponga de esa posible primera fuente -impresa o manuscrita - no tenemos prueba alguna de que la referencia a la «tierra de turcos» estuviese en el original de Rojas. 
En todo caso, en la versión de 1631 se restaura la frase omitida del original, pero con modificaciones en las otras no baladíes y que se comentarán más adelante.

Es de notar que Sedeño, en su refundición en verso de la Tragicomedia - impresa en Salamanca en 1540, es decir, equidistante de las traducciones de Ordóñez y Lavardin—, trasladaba el pasaje aludiendo a «tierra de moros»:

Si me quisiere vender / dentro de tierra de moros, / no rehuiré su querer ${ }^{13}$;

El testimonio de Sedeño tiene aquí su importancia por cuanto, a pesar de la poca estimación que Menéndez Pelayo sentía por sus «desaliñadas coplas de arte menor» (Menéndez Pelayo 1910: CLXIX), su autor «parece preocuparse más por la fidelidad al léxico del original que por su cuidadosa interpretación» (Blini 2009: Texto 35), lo que, sin embargo, no ocurre en este caso, donde la interpretación prima sobre la literalidad, a no ser que tuviera delante un texto de Rojas perdido en el que apareciera la referencia explícita a «tierra de moros» que sus traductores trasladarían como «tierra de turcos». Pero esto, de momento, es hipótesis no demostrada.

En el siglo XIX Germond de Lavigne, haciendo caso omiso de sus antiguos predecesores en el oficio, restituye el sentido original de la frase de Rojas. Cuál fuese el motivo de la sustitución italiana y el añadido francés está por averiguar. Con todo, las traducciones no parecen traicionar la intención del autor, aunque no sin algún reparo, como el que a continuación se hace.

\section{Breve casuística de la esclavitud}

Podía Melibea, en efecto, ser vendida como esclava en tierra de moros o de turcos. ¿Pero podía correr la misma suerte en los siglos XV, XVI o XVII una cristiana en tierras cristianas o en otras que sin serlo no estuviesen bajo el dominio del Islam, como era el caso de América?

De las islas descubiertas por Colón en su navegación atlántica podían traerse esclavos a Castilla, como de hecho hizo el Almirante, no sin escándalo de la reina, quien ordenó su liberación en tanto que vasallos de la Corona, pero malamente se podrían llevar y vender esclavos a tierras recién descubiertas cuyos pobladores andaban casi desnudos, sin oro que les adornara $y$, sobre todo, sin "secta» ni traza de imperio ninguno que pudiera constituirse en enemigo de Castilla o de la Cristiandad. Y no es que la institución de la esclavitud no existiese entre ellos, ni limitada a los

13.- Copio los tres versos de la edición de Lorenzo Blini de laTragicomedia de Sedeño publicada en la revista electrónica Lemir, 13 (2009), Texto 195. 
aztecas o los incas, como bien claro lo dejó dicho, entre otros cronistas de la época - y ya bien entrado el siglo xvI-, Álvar Núñez Cabeza de Vaca, quien habiendo pasado seis años como esclavo de los indios de la Florida, recordaba en sus Naufragios, relación dada a la imprenta en Zamora en 1542, cómo determinó de huir de ellos «por el mucho trabajo que me daban y el mal tratamiento que me hacían» (Núñez Cabeza de Vaca 1989: 134). Pero la trata, evidentemente, no se hacía con quienes en realidad solo los repartimientos y encomiendas les libraron del destino de los negros de Guinea, aunque no del sino de los vencidos.

¿Podría acaso Melibea, siendo ella cristiana, ser vendida como esclava en reinos asimismo cristianos? Salvador de Madariaga, en su biografía de Colón, mantenía que «desde el punto de vista político y religioso de Castilla, la esclavitud no podía tolerarse más que en el caso de prisioneros de guerra» (1979: 359). Y, efectivamente, ese era el caso más común, pero, como han demostrado investigaciones posteriores, la casuística de la época es más amplia. El mismo Madariaga recoge de la Historia de las Indias de Las Casas la noticia del apresamiento en 1487 u 88 del hermano de Cristóbal Colón por piratas corsarios en su viaje a Inglaterra desde Lisboa (1979: 325) y Graullera, en su estudio sobre la esclavitud en Valencia en los siglos XVI y XVII, afirma, bien respaldado con datos de archivo, que la fe, es decir, haber recibido el bautismo, no obstaculizaba en nada el cautiverio (1978: 132). Ni la raza ni la religión impedían que una mujer como Melibea - blanca y cristiana - pasase en España a la condición de esclava, sierva o cautiva, términos estos intercambiables si nos atenemos al Tesoro de Covarrubias. Tampoco que lo fuese en otros reinos cristianos que no con poca frecuencia eran enemigos de los de Castilla o Aragón, como lo fueron Francia y Portugal en vida de los Reyes Católicos. Así que a la citada frase de Melibea no se le puede dar la interpretación unívoca de referirse a tierra de moros o de turcos, por más que ese sea su sentido más probable.

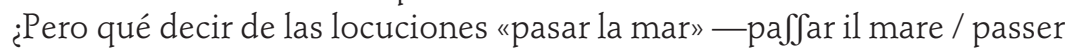
la mer / traverser les mers / passe the seas-y "rodear el mundo» —andar per tutto il mondo / tournoyer la terre / parcourir le monde / compase the world?

Para dilucidar el significado de las palabras de Fernando de Rojas, además de acudir a las traducciones, deberemos relacionar el problema fil lógico con las fechas de redacción e impresión de La Celestina y los testimonios más o menos próximos en que se documentan en español dichas locuciones - con sus distintas acepciones-, así como con los conocimientos geográficos y astronómicos en la Europa de finales del siglo XV y el grado de difusión de las noticias de los descubrimientos colombinos. 


\section{Imago mundi a finales del siglo $\mathrm{xV}$}

Si bien es verdad que decir que Colón descubrió América es un anacronismo y que el Almirante incluso murió creyendo haber llegado a Cipango por el oeste siguiendo la hipótesis de Toscanelli, no es menos cierto que sus errores lo fueron solo de cálculo. El proceso de incorporación de los nuevos conocimientos geográficos en la Edad Media fue lento y multisecular, pero la difusión de Tolomeo, cuya Geografía había sido traducida al latín en 1406-07, y los viajes de españoles y portugueses en el siglo XV obligaron a una amplia reconceptualización de la imagen medieval del mundo (Biglieri 2012: 22). Colón, por supuesto, no dudaba de la esfericidad de la Tierra, aunque más adelante, en su Relación del Tercer Viaje de 1498, cuando pensaba estar el Paraíso Terrenal en la desembocadura del Orinoco, precisara que su forma exacta se asemejaba más bien a una pera (Colón 1989: 213 y ss):

Yo siempre leí qu'el mundo, tierra e agua era espérico $\mathrm{e}<\mathrm{n}>$ las auctoridades y esperiençias que Ptolomeo y todos los otros qu'escrivieron d'este sitio davan... Agora... fallé que no era redondo en la forma qu'escriven, salvo que es de la forma de una pera que sea toda muy redonda, salvo allí donde tiene el peçón que allí tiene más alto, o como quien tiene una pelota muy redonda $y$ en un lugar d'ella fuesse como una teta de muger allí puesta, y qu'esta parte d'este peçón sea la más alta y más propinca al cielo.

La Teoría de la Esfera se confirmaba empíricamente. En 1473 los navegantes portugueses se adentraron por primera vez en el hemisferio sur. Las aguas del Mar de las Tinieblas no se podían desbordar en sus lejanos y nunca visitados horizontes del oeste para precipitarse en el vacío, como no lo hacían más abajo del Ecuador. Como en el hemisferio sur, el mar se prolongaba igualmente por occidente para abrazar las tres partes del mundo, que como tales aun seguían siendo las mismas que figuraban, según el Libro de Aleixandre (Anónimo 1988: 562 v. 2577), en «la mapamundi escripta e notada» de uno de los paños de la tienda de Alejandro de Macedonia, héroe de referencia tanto de Enrique el Navegante como de los Reyes Católicos.

Adentrarse y cruzar el mare tenebrosum no lo hacían imposible en el siglo XV los monstruos medievales ni la ausencia de una concepción justa de la forma esférica de la Tierra ni la falta de una tecnología capaz de llevar las naves que se orientaban con el astrolabio hasta los lejanos meridianos del Oriente apartándose de la costa y de los puertos. El proyecto de Colón, que hacía más corta la travesía entre la Península Ibérica y el Oriente, no fue rechazado por los portugueses porque lo creyeran descabellado, pues 
conocían a Toscanelli mejor que él, o porque desconfiaran de sus cálculos, sino por el temor a emprender un viaje sin retorno a causa de los vientos, lo que les inclinó a seguir contorneando África para llegar a las islas de las especias. En efecto, antes del primer viaje de Colón conocían los mareantes «...la constancia de los vientos aliseos, favorable a la navegación hacia el Oeste y contraria, por tanto, al regreso; y esta experiencia... que no pueril recelo o temor a lo desconocido... fue causa de repugnar la empresa propuesta por el Almirante» (Fernández Duro 1972: 119)14.

Frente al rechazo de los portugueses el proyecto de Colón fue fina mente aceptado por los reyes españoles para — según la tesis de Gustavo Bueno (1989: 3-32) - «coger a los turcos por la espalda», lo que prefigura el viaje de circunnavegación del Globo que en 1522 completaron Magallanes y Elcano. Colón en el último de sus cuatro viajes buscó infructuosamente el legendario estrecho del que hablaba Marco Polo, que permitiera salvar las islas y tierras tan inesperadamente descubiertas. Murió en 1506 en Valladolid sosteniendo con terquedad haber llegado a Asia, pero nadie pudo negarle ni entonces ni después la genialidad de haber abierto primero el derrotero hacia el Oeste aprovechando los vientos del este en la latitud de las islas Canarias y luego el que remontando la isla Española hacia el Ártico permitía encontrar los vientos variables que hacían posible el tornaviaje. Sin ello Juan de la Cosa no habría dibujado en su carta las costas del continente que a partir del planisferio de Waldseemüller daría en llamarse América ni Núñez de Balboa habría cruzado el istmo que separa los dos océanos.

El descubrimiento, conquista y colonización del Nuevo Mundo fue el resultado de la convergencia de la tecnología y la ciencia náuticas con la ambición de comerciar con oro, especias o esclavos, pero no menos lo fue de los designios políticos, imperiales, no exentos del ideal de una evangelización ecuménica, de quienes tras la toma de Granada recibirían el título de Reyes Católicos.

La conquista de las Indias fue desde esta perspectiva no un desvío, sino una continuación de la política africana. Cisneros, cardenal de Toledo, confesor de la reina y regente, tras su muerte, de Castilla «...comparte la ilusión de muchos de sus contemporáneos, que soñaban con irse «a tierra de moros» y morir por la fe y por la conversión de los infieles en una campaña que culminaría con la liberación de la Tierra Santa y de Jerusalén» (Pérez, Joseph 2015: 140). El ideal de la Cruzada se entrevera con la pervivencia de las ideas de Ramón Llull (1232-1315), tan influyentes aun a finales del siglo XV, por lo menos en medios franciscanos, orden a la que pertenecía Cisneros y cuyos misioneros fueron en seguida enviados a las Indias. Llull «estaba convencido de la existencia en la otra parte del mun-

14.- Cesáreo Fernández Duro (1830-1908), capitán de navío y miembro de la Real Academia de la Historia y de Bellas Artes de San Fernando, vio publicada su obra en 1895. 
do, de unas tierras desconocidas pobladas por hombres sin secta, es decir, por paganos que no eran idólatras y que, por lo tanto, serían más aptos para convertirse al cristianismo» (Pérez 2015: 141).

En la universidad fundada por el cardenal Cisneros iba a primar el estudio de las lenguas orientales y el griego, lo que culminaría con la impresión de la Biblia Políglota para fijar un texto en que leer y predicar sin error. En la de Salamanca la exégesis bíblica, la Teología — con título ya oficial desde su emancipación de La Sorbona tras la licentia ubique docendi de 1416-y el Derecho canónico se combinaban con los estudios de Derecho civil — que tal vez estudiara aquí el bachiller Fernando de Rojas-y de otras disciplinas: Lógica, Retórica, Gramática, pero también matemáticas y cosmografía. En su rica biblioteca (Becedas 2002) junto a joyas de la literatura - hasta hoy se conserva un códice manuscrito del Libro de Buen Amor o una copia del Cancionero de Palacio, por ejemplo-, se atesoraban muchas otras de las más diversas materias, como los Elementa geometrica de Euclides - que se enseñaban en la cátedra de Matemáticas- o la Cosmographia cum figuris de Pomponio Mela, impreso en Salamanca en 1498.

Hacia 1460 la universidad de Salamanca crea una cátedra de Astrología, apenas dos décadas después Abraham Zacut publica su gran obra astronómica, La gran composición; Diego Torres —asesor de los Reyes Católicos para la delimitación de los dominios marítimos de España y Portugal en el Tratado de Tordesillas - ocupa dicha cátedra entre 1481 y 1496, Elio Antonio de Nebrija da a la imprenta su Introductorium cosmographie, obra en la que —en palabras de Flórez Miguel — el gran cosmógrafo salmantino distingue el "viejo mundo» conocido por Ptolomeo y el «nuevo mundo" descubierto por los marinos castellanos y portugueses «diferenciando perfectamente las «dos rutas» abiertas por los navegantes: la ruta Atlántica que lleva a América y que él [Nebrija] sitúa correctamente en el mapa; y la ruta africana como un nuevo camino para llegar a Asia» (2011: 194).

\section{Difusión de las noticias del Descubrimiento}

La difusión en grande de libros impresos había de esperar al siglo XVI y aun así muchos manuscritos con información relevante de itinerarios marítimos nunca se dieron a la imprenta, probablemente por mantener el secreto militar. Cartógrafos y marinos de la Casa de la Contratación, que fundara el rey Fernando el Católico en 1503, deberían abstenerse de divulgar todo lo que pudiera ser utilizado por los enemigos o competidores de los reinos de Castilla y Aragón. Esta censura impidió la impresión, aunque siendo ya rey de Castilla Carlos V, de obras como el Espejo de navegantes de Alonso Chaves, por ejemplo (Fernández 1972: 341).

A pesar de la censura por razones de índole política o militar, las noticias traídas por los marinos, oficiales y grumetes que regresaban a los 
puertos y a sus pueblos de origen difícilmente podrían constreñirse a los centros de poder, ya fuera la Corte o las universidades. Antes al contrario, es más plausible que corrieran como la pólvora y se difundieran de boca en boca y que la nueva imagen del mundo que se estaba creando fuese compartida por todo tipo de gentes de todos los cuerpos sociales y pasaran fácilmente a la literatura escrita y de transmisión oral.

La primera noticia impresa del descubrimiento del Nuevo Mundo fue el texto de la carta que Cristóbal Colón, al final de su primer viaje, dirigió a Luis de Santángel: «...vos escribo ésta, por la cual sabréis como en setenta y un días pasé las Indias con la armada que los ilustrísimos Rey y Reina nuestros señores me dieron». La carta, publicada en Barcelona en 1493, había alcanzado dieciocho ediciones en cuatro idiomas al acabar el siglo, según recuerda López Piñero en El arte de navegar en la España del Renacimiento (1979: 78).

Antes de que Colón regresara de su segundo viaje los Reyes daban licencia a quienes en Castilla querían «ir a descobrir otras islas e tierra firme a las partes de las Yndias en el mar Océano", siempre que no entraran en lo ya hallado por Colón (Gil 1986: 50-53), lo que se ordenó pregonar y publicar «en todas las cibdades e villas e logares e puertos del Andaluzía e otras partes de nuestros reinos donde conviniere». La abundante documentación que registra Juan Gil en la obra citada da cuenta de la rápida difusión de las noticias de los descubrimientos. En 1494 se piensa en enviar hasta un millar de hombres a poblar las Indias, en 1495 se da orden de retirar a inútiles y maleantes... Entre los enrolados para uno de los viajes, además de marineros y grumetes, hay lavadores de oro, pero también albañiles, aperadores y gañanes, y no todos hombres, a un tal Alfonso de Espinosa le acompaña su mujer (Gil 1986: 148). En el documento notarial en que Colón solicita un Mayorazgo, seguramente anterior al Tratado de Tordesillas de 1497, se insiste en esta idea de «poblar e descubrir más»(Colón 1989: 190). En el tercer viaje de Colón, de 1498, ya son seis las carabelas que salen del puerto de Sanlúcar (Colón 1989: 205 nota 15).

La conclusión no puede ser otra: "Las Indias han entrado ya en la vida cotidiana de los españoles» (Gil 1986: 62). Difícilmente tales nuevas dejarían de llegar a los oídos de un bachiller de Salamanca, lector probablemente de alguno de los «breves tratados didácticos de geografía en los que se sistematiza una imagen del mundo, que está destinada a conformar la mentalidad de los hombres cultos de su momento ya sean reyes, príncipes, nobles, clérigos y demás estamentos que forman el llamado público culto» (Flórez 2011: 192).

En medio de las disputas entre teólogos y filósofos o entre escolásticos y humanistas, la modernidad se instala en la universidad. Fray Diego de Deza - el mediador entre Colón y los reyes- ocupa la cátedra que no muchos años después obtendría Francisco de Vitoria, el fundador de la 
"Primera Escuela de Salamanca». Ya fuera en la universidad en su años más jóvenes o fuera de ella el autor de la Tragicomedia de Calisto y Melibea no podía permanecer ajeno, mientras la escribía, al «Descubrimiento de un Nuevo Mundo» ${ }^{15}$.

\section{Pasar la mar y rodear el mundo: acepciones y etimologías}

En la entrada correspondiente a "Andar» del Diccionario de la lengua española de la RAE (23. ${ }^{a}$ edición, año 2014) se afirma que es una variante romance del latín ambulare, y como primera acepción aparece así definido: "Dicho de un ser animado: Ir de un lugar a otro dando pasos». La segunda acepción reza así: "Dicho de algo inanimado: Ir de un lugar a otro. Andar los planetas, la nave». Es decir, que se puede andar así por tierra como por mar (y hasta por las nubes).

"Rodear», formado de rueda y -ear, es, en la segunda acepción del mismo diccionario, "Cercar algo cogiéndolo en medio", en la quinta "Andar alrededor» y en la sexta "Ir por camino más largo que el ordinario o regular».

En el Breve diccionario etimológico de la lengua castellana de Corominas el uso de "Andar» se data en la segunda mitad del siglo x y se afirma que es término procedente de amlare, forma romance derivada de la pronunciación descuidada del latín ambulare.

«Rodear» aparece en la entrada dedicada a «rueda» y se data en 1335.

a) "Rodear el mundo».

¿Rodear el mundo» —en la traducción italiana «andar per tutto il mondo»- debe entenderse como el camino que se hace "a pie enjuto o a caballo por la tierra (entonces) conocida» hasta aventurarse por aquellas de las que se había alcanzado noticia, aunque aun no hubieran sido holladas, es decir, la de las tres partes del mundo - Europa, Asia y África- de los antiguos $\mathrm{T}-\mathrm{O}$, que seguían siendo las de los nuevos mapas, tal como hicieran Marco Polo en el siglo xiII o Pero de Covilha y Afonso de Paiva cuando fueron enviados en 1487 por el rey Joao II en busca del reino cristiano del Preste Juan?, ¿o se le debe dar el significado de «dar la vuelta al mundo (entonces conocido) siguiendo su contorno», es decir, seguir la ruta de los navegantes portugueses que ya habían doblado el cabo de las Tormentas, luego llamado de Buena Esperanza, en el viaje de 1487-88 de Bartolomeu Dias y que diez años más tarde, en 1497, también siguió Vasco de Gama para llegar a la India o a las islas de las Especias?, ¿sería acaso

15.- Para conocer «la estructura de los saberes» impartidos en Salamanca y el ambiente social en que se movían alumnos y maestros en los años en que Rojas estudió allí puede leerse La Primera Escuela de Salamanca (1406-1516), (Flórez, 2012) donde se defiende la primacía de este título para los predecesores de Vitoria. 
excesivo darle a la locución el sentido de seguir la ruta colombina por el oeste y "circunnavegarlo», como finalmente harían Magallanes y Elcano, terminando de dar la vuelta al globo terráqueo en 1522, expedición que Antonio Pigafetta, uno de los pocos supervivientes que lograron regresar al punto de partida, registró por menudo en su Relazione del primo viaggio intorno al mondo ${ }^{16}$ ?

Cuando Fernando de Rojas escribiera la Tragicomedia, cuya edición princeps puede, con las debidas precauciones, datarse en 1502 (Serés 2000: LXXX) ${ }^{17}$, el mapa mundi estaba siendo rápidamente redefinido —el mapa de Toscanelli fue sustituido por el de Juan de la Cosa en 1500. Colón en su Relación del Tercer Viaje instaba a los Reyes Católicos a emular a los de Portugal en su empresa de Guinea para ser "los mayores señores del mundo, digo señores de todo él» (Colón 1989: 236).

No puede descartarse, a mi juicio, que en los planes geoestratégicos de los reyes españoles figurase ya la "circunnavegación» del entero globo terráqueo, que no tardaría mucho en cumplirse, aunque con rumbo bien distinto tras las constatación de la existencia de un nuevo continente.

Que tal posibilidad se estaba debatiendo, aunque con conciencia de su dificultad, puede deducirse de testimonios como el que dejó en su Historia de los Reyes Católicos Andrés Bernáldez, el cura de Los Palacios:
... que por la banda que el Almirante buscaba el Catayo, es mi creer, que con otras 1200 leguas andando el firm - mento de la Mar e tierra en derredor no llegara. Y ansí se lo dije i hize entender yo el año de 1496 (Bernáldez, Mss/619: 179)

Como parece arriesgado considerar ese "rodear el mundo» que Rojas pone en labios de Melibea una temprana referencia a su circunnavegación, por mucho que ya pudiera teóricamente contemplarse, puede intentarse otra aproximación al sentido de la frase acudiendo a las traducciones.

16.- Con este mismo título aparece en la versión italiana que preparó Camillo Manfroni (Milano: Istituto editoriale italiano, 1956), fiel a la copia manuscrita del original de Pigafetta que se conserva en la Biblioteca Ambrosiana. En la traducción española que publicó EspasaCalpe en 1941 en su Colección Austral el título de portada es Primer viaje en torno del Globo, pero en realidad el relato se abre con el título deViaje alrededor del mundo, tras aclarar los editores que se limitaron a traducir la versión francesa - Premier voyage autour $d u$ monde...- que hizo Carlos Amoretti en 1801 en París (chez H.J de Jansen) a partir de su versión expurgada y puesta «en buen italiano». La versión de Amoretti fue editada un año antes en Milán siguiendo, según el mismo afirmaba, la copia manuscrita del original de Pigafetta, «mezcla de italiano, de veneciano y de español» (Amoretti 1963: 34).

17.- Serés recoge aquí la hipótesis de Moll. La llamada de atención de Di Camillo (2012: 216-226) sobre la inexistencia de testimonios de una princeps de la Tragicomedia y la posibilidad de que la traducción italiana de Ordóñez se basara en un ejemplar perdido de la misma sigue en vigor, pero a lo sumo su aparición se adelantaría a 1501 o, como sugiere Patrizia Botta (1999), a 1500, fecha de la supuesta edición perdida de Salamanca que, constituída en princeps de la Tragicomedia, habría servido de base para la edición valenciana de Joffre de 1514. 
Lavardin bien pudo haber deshecho todo equívoco, ya que tradujo la Tragicomedia muchos años después del viaje de Elcano, dando a la frase el sentido preciso de "dar la vuelta al mundo» tal como hoy lo entenderíamos, si es que eso es lo que pensó que Rojas quería decir. Pero lo cierto es que prefirió utilizar viejas locuciones de sabor medieval, tal vez por tener conciencia del problema histórico que planteaba la interpretación y, por tanto, la traducción de la frase de Melibea.

La locución francesa «tournoyer la terre» no aparece tal cual en el Dictionnaire du Moyen Français (1330-1500), pero recoge voces relacionadas con el verbo que clasifica en dos apartados. El segundo, bajo el epígrafe de "Prendre part à un tournoi, combattre, jouter», es decir, «tomar parte en un torneo", y el primero, que es el que aquí interesa, bajo el de "tourner». Entre las entradas correspondientes a este apartado figuran algunas que describen un movimiento circular, ya el que da alguien sobre si mismo, ya el que se da alrededor de algo ${ }^{18}$, pero también hay otras en que el sentido es regresar al punto de partida sin apariencia de movimiento circular en sentido estricto. Finalmente, la entrada «Tournoyer un lieu» se describe como "Parcourir (un lieu) en tous sens, sans but précis», es decir, con la idea de andar errante sin una meta precisa (DMF 2015).

Es difícil adscribir la traducción de Lavardin a solo una de estas distintas acepciones con exclusión de otras, de modo que no por usar una locución antigua, sino por no usar otra más moderna y posible en sus días, podemos deducir que el sentido que quiso dar a la frase de Melibea en su traducción no es el de dar la vuelta al mundo, sino el de caminar errante y sin meta, como hacían los caballeros andantes de los libros de caballerías, lo cual no obsta — dicho sea de paso- para que el personaje de Rojas fuese menos medievalizante de lo que Lavardin pudiera suponer.

En cuanto a la traducción de Mabbe - "Yf he will compase the world»que, recordemos, tuvo a la vista tanto la traducción francesa como el texto de Rojas, la elección de un verbo ligado al uso de la brújula o aguja marina ("a sea compas») lleva la idea francesa de "tournoyer la terre» a la de navegarla, y no sin rumbo, aunque tal vez sin meta. Pero en la versión de 1631 la frase se traduce en términos que parecen aludir a la idea de «rodear el mundo» en un sentido moderno, que bien podría referirse a la de su circunnavegación: «if hee will round the world».

En vista de los testimonios aducidos no se puede afirma, pero tampoco negar, que Rojas diera a las palabras de Melibea el sentido de dar la vuelta al mundo circunnavegándolo. Otra cosa es que se pueda legítimamente poner en duda que Rojas se adelantara a los hechos en veinte años, pero

18.- La entrada «Tourner (dans un certaine espace)» se ilustra con un ejemplo de principios del siglo XV: «Et les natures de chascune M'aprist et de souleil et lune Les mouvemens et les eclipses, Et comment par sus les eclipses Des cercles le souleil s'en monte Et va tout parmi l'orizonte Des douze signes tournoaiant, Et fait son tour tout en roiant Environ le ciel en un jour Et en une nuit sanz sejour». 
también queda dicho que el proyecto como tal estaba ya en marcha y se estaba discutiendo y que, por tanto, la amplificación retórica podría ser no una alusión a lo imposible, sino, muy al contrario, a lo ya factible.

En el capítulo V de la Segunda parte del ingenioso caballero don Quijote de la Mancha Sancho Panza encomienda a su mujer Teresa Panza que cuide del rucio en los días previos a la anunciada tercera salida de don Quijote, ya que piensa acompañarle de nuevo: «...dobladle los piensos, requerid la albarda y las demás jarcias, porque no vamos a bodas, sino a rodear el mundo y a tener dares y tomares con gigantes, con endriagos...» (Cervantes 1998: 664). Todavía no había visto ni lo pensaba ver Sancho el mar en las playas de Barcelona. Ese «rodear el mundo» debería ser por tierra enjuta, como lo hicieran don Polindo y don Claribeo en la novela anónima de 1526:

E yendo don Polindo por el camino, dixo don Claribeo: «Señor, pues ya somos salidos de la corte, conviene si a vós, señor, os paresce, que vamos a rodear el mundo para ganar más honra, por donde nuestras señoras más de nosotros sean estimadas». "Bien sabe, señor — dixo don Polindo-, que nunca salí de vuestro mandado; menos saldré agora, que tanto os devo. Lo que a mí me paresce, que vamos a Costantinopla e de allí andaremos a otras partes». Y ansí acordaron de andar a sus aventuras. Y así tomaron su camino para Costantinopla. Y caminando, ivan hablando en sus señoras... ${ }^{19}$

La locución "rodear el mundo" había entrado en el dudoso terreno de las anfibologías. En los textos de la época al viejo significado se yuxtapone la nueva percepción que se obtuvo del mundo tras la comprobación empírica de la Teoría de la Esfera. Tras el viaje de Magallanes y Elcano el mundo también podía rodearse navegando. La desambiguación exigía precisión. Pedro Medina, conocido sobre todo por sus tantas veces traducido Arte de navegar, en su Libro de grandezas y cosas memorables de España (1548: Miniatura 83) lo hace mediante una aparente redundancia:

Assi lo avemos visto en nuestos tienpos que por la naue-
gacion de los españoles a sido dada buelta a todo el
vniuerso en tal manera que saliendo de España y guian-
do contra Poniente Rodeando en derredor todo el mun-
$\underline{\text { do an uelto a ella por el levante. Cossa es esta tan grande }}$

19.- Es, con la misma acepción del fragmento de Cervantes, el testimonio de la expresión más cercano a La Celestina de Rojas que hemos encontrado en el Banco de datos CORDE [en línea] de la RAE (Corpus diacrónico del español) <http://www.rae.es>. Aunque el libro no lo he tenido a la vista, habiéndome limitado a la consulta del CORDE, anoto en la Bibliografía -Anónimo- la edición que de esta obra hizo Manuel Calderón Calderón. 
que despues que dios crio el Mundo: nunca tal se hizo ni penso / ni aun creyo ser possible.

Seguramente Melibea está en esto más cerca de los caballeros andantes, que dejaban a la voluntad de sus caballos el «hacer rodeos», que de los navegantes renacentistas que quisieron "andar a la redonda" el mundo, es decir, "todo el círculo de tierra y mar», tal como lo definía Covarrubias en su Tesoro, pero la imagen marinera de Mabbe nos devuelve - circularmente - al punto de partida.

b) Pasar la mar

¿"Pasar la mar», en boca de Melibea, se refería al Mediterráneo?, ¿se podría referir al Mar Océano? En apoyo de ambas lecturas pueden aducirse algunos ejemplos.

La reconquista de los Santos Lugares era un ideal cristiano - asociado a la idea de imperio universal- compartido por las monarquías castellana y aragonesa. Frente a ellas se alzaba otro, el Islam, que, aunque había perdido Granada, seguía siendo una amenaza en África y cortaba las vías de comunicación en el Meditarráneo. La guerra de Granada —afirma Fernández-Armesto (2011: 40)— es preciso «interpretarla en el contexto del enfrentamiento general contra el creciente poder de los turcos del Imperio otomano, al que los monarcas españoles percibían como sus enemigos más temibles a largo plazo».

La literatura caballeresca ya recogía este conflicto y aquella ambición. En El Victorial de Gutierre Díez de Games, aparecido en la primera mitad del siglo XV, dice el ayo a Pero Niño para que se guarde de las falsas profecías:

E si bien paras mientes, como biene rey nuevo, luego fazen Merlín nuevo. Dizen que aquel rey a de pasar la

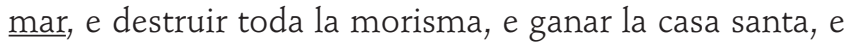
de ser enperador; e después veemos que se faze como a Dios plaze (1940: 68).

Si nos atenemos a testimonios como el citado, de larga tradición medieval —valga de muestra el popular Romance del moro Calainos: "Por tus amores, Sevilla, pasé yo la mar salada» (Anónimo 1981: 188, v. 42)— habrá que dar a la locución el sentido de cruzar el Mediterráneo. Sin embargo, ha de tenerse en cuenta la distancia temporal que separa El Victorial de la publicación de La Celestina.

No podemos saber la fecha de redacción de la Comedia de Calisto y Melibea, pero, al menos, su edición princeps no puede alejarse mucho ni de la de Burgos de Fadrique de Basilea de 1499 (o 1502) ni de las de Toledo de 1500 y de Sevilla de 1501. En cuanto a la Tragicomedia, su edición princeps, también perdida, podría datarse — como ya se ha dicho- entre 1500 y 1502; en cualquier caso, y como es obvio, no después de la traducción italiana de Ordóñez de 1505. Es decir, La Celestina aparece mientras se 
suceden los viajes colombinos, cuando ya ha pasado más de medio siglo desde la redacción de El Victorial.

En cuanto a las traducciones que manejamos, Ordóñez y Lavardin conservan el singular al traducir "la mar» del original de Rojas. Mabbe, sin embargo, usa ya el plural, al menos en su primera versión, como lo haría Germond de Lavigne en el siglo xIx. Todo podría reducirse a mera amplificación retórica, pero cabe la duda de que ese plural inglés del siglo XVII recoja y exprese una concepción geográfica del mundo y de sus mares ya presente entre los contemporáneos de Rojas, la de un Oceano navegable - y pronto navegado-, idea que podría así contarse entre las distintas opciones de huída de Melibea.

\section{Este mundo es pequeño}

Si La Española o alguna de sus islas adyacentes era, como Colón creía, la bíblica Ofi, la clásica Tapróbana o la medieval Cipango, no es extraño que apostillara al leer el ejemplar que poseía de la Imago mundi de Pedro d'Ailly: "Observa que si la Tapróbana está como dicho queda, distaría del verdadero Occidente [Canarias] 58 grados al Zéfiro [el Oeste]. Por lo tanto, decimos bien que entre España y la India media un mar pequeño ${ }^{20}$.

Ese cálculo y esa consideración permiten — sin prueba, pero sin escándalo- interpretar la frase de Melibea «si pasar quiere la mar» como referida al Oceano, pues según el Almirante en su Relación del Tercer Viaje, de 1498, —en realidad un extracto del original perdido escrito por Bartolomé de las Casas-y siguiendo aquí a Aristóteles, «este mundo es pequeño y es el agua muy poca y... fácilmente se puede passar de España a las Yndias» (Colón 1989: 217), idea que reitera en 1503 en su Relación del Cuarto Viaje apoyándose ahora en la autoridad de Tolomeo: «El mundo es poco; el injuto d'ello es seis partes, la séptima solamente cubierta de agua. La experiençia ya está vista... Digo que el mundo non es tan grande como diçe el vulgo». (Colón 1989: 320).

No sabemos con certidumbre si el bachilller en Leyes, que el famoso acróstico declara ser Rojas, se había limitado a estudiar los tres años preceptivos en la Facultad de Artes "para cursar el bachilleramiento» o si, por el contrario, en verdad alcanzó en la Facultad de Leyes el grado de bachiller, inferior al de licenciado, pero que exigía estudiar durante seis años (Serés 2000: LXVIII).Tampoco podemos precisar hasta qué punto el joven Rojas y otros como él pudieron beneficiarse de los conocimientos geográficos que atesoraba la biblioteca de la universidad de Salamanca o se difundían desde las cátedras Pero para una reconstrucción de la biogra-

20.- La cita la he extraído de "Mito y realidad en la empresa colombina» (p. 67), estudio preliminar de Juan Gil que acompaña a su edición de El libro de Marco Polo que queda consignado en la Bibliografía. 
fía del aun enigmático autor de la Tragicomedia de Calisto y Melibea puede ser interesante indagar — que es lo que aquí se ha intentado- si la nueva imagen del mundo que Cristóbal Colón hizo posible entre sus contemporáneos e inauguró la modernidad se reflejó en su obra.

Siete años había pasado Colón intentando vencer incredulidades y resistencias hasta alzarse con la aprobación de los reyes y poder escribir en el comienzo del Diario del Primer Viaje: «Vuestras Altezas... pensaron de enbiarme a mí, Cristóval Colón, a las dichas partidas de India... y ordenaron que yo no fuese por tierra al Oriente, por donde se acostumbra de andar, salvo por el camino de Occidente, por donde hasta oy no sabemos por cierta fe que aya passado nadie» (Colón, 1989: 15-16).

Ese camino de Occidente habría de ser prontamente recorrido por los galeones que a lo largo de los siglos XVI y XvII llevarían en su carga desde Sevilla hasta los virreinatos de Nueva España o del Perú, entre otras mercadurías, centenares de libros, y entre ellos algunos ejemplares de La Celestina (Rueda 2004: 101-116). Tal vez les precediera — si se me permite el anacronismo vespucciano- «el sueño americano» de Melibea. 


\section{Bibliografía citada}

AnÓnimo (1981), «Romance del moro Calaínos» en El Romancero Viejo, ed. Mercedes Díaz Roig, Madrid, Cátedra.

Anónimo (1988), Libro de Alexandre, ed. Jesús Cañas, Madrid, Cátedra.

Anónimo (2003), Polindo, ed. Manuel Calderón Calderón, Alcalá de Henares, Centro de Estudios Cervantinos.

AmoretTi, Carlos (1963), «Prefacio del traductor francés» en Pigafetta, Antonio, Primer viaje en torno del Globo, Madrid, Espasa-Calpe.

BeCEDAS, Margarita (2002), Tesoros de la Antigua Librería de la Universidad de Salamanca, Salamanca, Ediciones Universidad de Salamanca.

Bernaldez, Andrés, "Como fue a descobrir el Almirante» Capítulo 123, en Historia de los Reyes Católicos Don Fernando y Doña Isabelh [Manuscrito] escrita por el Bachiller Medina, cura de los Palacios, capellán de Diego Deza y Arzobispo de Sevilla, en BNE-Biblioteca Digital Hispánica, (Signatura: Mss/619), 328h.

Bigleri, Anibal A. (2012), Las ideas geográficas y la imagen del mundo en la literatura española medieval, Madrid, Iberoamericana / Vervuert.

BuinI, Lorenzo (2009), "Introducción» a su edición de Tragicomedia de Calisto y Melibea. Nuevamente trobada y sacada de prosa en metro castellano por Juan Sedeño, Revista electrónica Lemir, núm. 13, Textos, pp. 31-47.

BotTA, Patrizia (1999), "El texto de La Celestina en la edición de Valencia, 1514», en op. cit. Rojas, Fernando de (1999), pp. 17-29.

BotTA, Patrizia y Elisabetta VACCARO (1992), «Un esemplare annotato della Celestina e la traduzione inglese di Mabbe», Cultura Neolatina LII, Fasc. 3-4, pp. 353-419.

Bueno, Gustavo (1989), "La Teoría de la Esfera y el Descubrimiento de América», El Basilisco, 2. época, num.1, pp. 3-32.

Cervantes, Miguel de (1998), Segunda parte del ingenioso caballero don Quijote de la Mancha, ed. Francisco Rico, Barcelona, Instituto CervantesCrítica.

Colón, Cristóbal, (1989), "Diario del Primer Viaje», en Cristóbal Colón. Textos y documentos completos, ed. Consuelo Varela, Madrid, Alianza Universidad.

— «Documento notarial» en op.cit. Cristóbal Colón. Textos y documentos completos.

—. «Relación del Tercer Viaje» en op.cit. Cristóbal Colón. Textos y documentos completos.

—. «Relación del Cuarto Viaje» en op.cit. Cristóbal Colón. Textos y documentos completos.

CovarRubias, Sebastián de (1979), Tesoro de la lengua Castellana o Española, [Original impreso en 1611], Madrid, Turner. 
Corominas, Joan (1973), Breve diccionario etimológico de la lengua castellana, [1. ' edición 1961], Madrid, Gredos.

Di Camillo, Ottavio (2012), "Algunas consideraciones sobre la Celestina italiana", Rumbos del hispanismo en el umbral del Cincuentenario de la AIH 8 vols. (coord. Patrizia Botta), Roma, Bagatto Libri, vol. II Medieval, pp. 216-226. PDF del art. en <http://www.academia.edu/2332985/>, pp. 1-17.

Dímz de Games, Gutierre (1940), El Victorial, ed. J. de M. Carriazo, Madrid, Espasa-Calpe.

DMF (2015), Dictionnaire du Moyen Français, <http://www.atilf.fr/dmf>, ATILF-CNRS \& Université de Lorraine.

FERnÁNDEZ-ARMesto, Felipe (2011), 1492 El nacimiento de la modernidad, Barcelona, Debolsillo.

Fernández Duro, Cesáreo (1972), Armada española, Madrid, Museo Naval. Flórez Miguel, Cirilo (2011), "Las Ciencias y la Universidad de Salamanca en el siglo XV», Salamanca y su Universidad en el Primer Renacimiento: siglo XV. Miscelánea Alfonso IX, 2010, eds. Luis E. Rodríguez-San Pedro Bezares y Juan Luis Polo Rodríguez, [Núm. 175 de la Colección «Aquilafuente»], Salamanca, Ediciones Universidad de Salamanca, pp. 179-201.

- et al. (2012), La Primera Escuela de Salamanca (1406-1516), [Núm. 183 de la Colección "Aquilafuente»], Salamanca, Ediciones Universidad de Salamanca.

GiL, Juan (1986), "Mito y realidad en la empresa colombina», en El libro de Marco Polo. Ejemplar anotado por Cristóbal Colón, Madrid, Testimonio, pp. 15-107.

Gómez Moreno, Ángel (2009) "La torre de Pleberio y la ciudad de La Celestina», El mundo social y cultural de La Celestina, eds. Ignacio Arellano y Jesús M.Usunáriz, Madrid, Iberoamericana, pp. 211-236.

Graullera Sanz, Vicente (1978), La esclavitud en Valencia en los siglos XVI y XVII, Valencia, Consejo Superior de Investigaciones Científicas

KisH, Kathleen V. (1973), "An edition of the first Italian translation of the Celestina", Studies in the Romance Languages and Literatures 128, Chapel Hill, The University of North Carolina Press.

Lida de Malkiel, María Rosa (1962), La originalidad artística de 'La Celesti$n a^{\prime}$, Buenos Aires, Eudeba.

López Piñero, José María (1979), El arte de navegar en la España del Renacimiento, Barcelona, Labor.

Madariaga, Salvador de (1979), Vida del muy magnífico señor don Cristóbal Colón, Madrid, Espasa-Calpe.

Maravall, J.A. (1964), El mundo social de La Celestina, Madrid, Gredos.

Martínez Lacalle, Guadalupe (1972), "Introduction» a su edición de Celestine or the Tragick-Comedie of Calisto and Melibea, Translated by James Mabbe, London, Tamesis, pp. 1-102. 
Medina, Pedro de (1548), Libro de grandezas y cosas memorables de España, Sevilla, en BNE- Biblioteca Digital Hispánica, (Signatura: R/31730), pp. [9], CLXXXVI h.

Menéndez Pelayo, Marcelino (1910), Orígenes de la novela, Tomo III, Madrid, Baillly // Bailliére.

Monsalvo Antón, José M. (2011), "Poder y cultura en la Castilla de Juan II», Salamanca y su Universidad en el Primer Renacimiento: siglo XV. Miscelánea Alfonso IX, 2010, [Núm. 175 de la Colección «Aquilafuente»], eds. Luis E. Rodríguez-San Pedro Bezares y Juan Luis Polo Rodríguez, Salamanca, Ediciones Universidad de Salamanca, pp. 15-91.

Muñón, Sancho de (1977), La Tercera Celestina. Tragicomedia de Lisandro y Roselia, edición facsímil de la editada en 1921 por Joaquín López Barbadillo, Madrid, Akal.

Núñez Cabeza de Vaca, Álvar (1989), Naufragios, ed. Juan Francisco Maura, Madrid, Cátedra.

Pérez, Joseph (2015), Cisneros, el cardenal de España, Barcelona, Taurus / Fundación Juan March - Penguin Random House.

Piccolomini, Eneas Silvio (2006), Cintia / Historia de dos amantes, ed. y tr. José Manuel Ruiz Vila, Madrid, Akal.

PigafetTa, Antonio (1956), Relazione del primo viaggio intorno al mondo, ed. Camillo Manfroni, Milano, Istituto editoriale italiano.

Rojas, Fernando de (1975), Tragicomedia de Calixto y Melibea, facsímil de la edición de Valencia, Juan Joffre, 1514; 70 hoj.; 4 . Espasa-Calpe, Madrid.

-. (1984), Tragicomedia de Calixto y Melibea. Libro también Llamado La Celestina, eds. M. Criado de Val y G.D. Trotter, Reimpresión de la $3^{a}$ edición (1 $1^{a}$ edición 1958), Madrid, Consejo Superior de Investigaciones Científicas

-. (1999),Tragicomedia de Calisto y Melibea (Valencia, Juan Joffre, 1514) edición paleográfica de Nicasio Salvador Miguel y Santiago LópezRíos, Valencia, Institució Alfons el Magnànim.

-. (y "Antiguo autor») (2000), La Celestina. Tragicomedia de Calisto y Melibea, eds. Francisco J. Lobera y Gillermo Serés, Paloma Díaz-Mas, Carlos Mota e Íñigo Ruiz Arzálluz, y Fracisco Rico, Barcelona, Crítica. - (2001), La Celestina. Comedia o Tragicomedia de Calisto y Melibea, ed. Peter E. Russell, Madrid, Castalia

Rueda Ramírez, Pedro J. (2004), «La Celestina camino de América. El libro en circulación en la Carrera de Indias (siglos XVI-XVII) ", Celestinesca 28, pp. 101-116.

RuselL, Peter E. (2001), «Nota 22 a pie de pg. 547» de su edición de La Celestina (2001), op.cit, Madrid, Castalia.

SColes, Emma (1961), "Note sulla prima traduzione italiana della Celestina», Studj Romanzi XXXIII, pp. 155-217. 
Sedeño, Juan (2009), Tragicomedia de Calisto y Melibea. Nuevamente trobada y sacada de prosa en metro castellano por Juan Sedeño, ed. Lorenzo Blini, Revista electrónica Lemir, núm. 13. Textos, pp. 49-234.

Serés, Guillermo (2000), "Primeros textos y Fortuna editorial» en op.cit. Rojas, Fernando de (y "Antiguo autor»), La Celestina. Tragicomedia de Calisto y Melibea, pp. LXXII-XCI.

—. «Rojas y el antiguo autor», en op. cit. Rojas, Fernando de (y «Antiguo autor»), La Celestina. Tragicomedia de Calisto y Melibea, pp. LVIII- LXXII.

Silva, Feliciano de (1988), Segunda Celestina, ed. Consolación Baranda, Madrid, Cátedra.

\section{Traducciones}

LAVARDIN, Jacques de.

Rojas, Fernando de (1578), La Celestine fidellement repurgee et mise en meilleure forme par Iacques de Lavardin. A Paris. Pour Gilles Robinot, MDLXXVIII. (Es la edición que utilizó Drysdall para su estudio y edición de la traducción francesa de Lavardin. En la BNE se conserva un ejemplar editado «par Nicolas Bonfons» del mismo año de 1578. Signatura: R/41530)

ROJAS, Fernando de (1974), La Celestine in the French translation of 1578 by Jacques de Lavardin, ed. Denis L. Drysdall, London, Tamesis.

Lavigne, A. Germond de.

Rojas, Fernando de (1873), La Célestine, Tragi-comédie de Calixte et Mélibée, Traduite de l'espagnol et annotée par A. Germond de Lavigne, Nouvelle édition revue et complétée, Paris, Alphonse Lemerre, 1873. (Imprimé chez Alphonse LEMERRE, libraire 27-29, passage Choiseul) MDCCCLXXIII. (Ejemplar de Biblioteca Nacional de España: signatura: $1 / 245646)$

MABBE, James.

RoJAS, Fernando de (1631), The Spanish Bawd. Represented in Celestina or The Tragicke-Comedy of Calisto and Melibea, London. (Ejemplar de la BNE: signatura R40850).

Rojas, Fernando de (1972), Celestine or the Tragick-Comedie of Calisto and Melibea, Translated by James Mabbe, ed. Guadalupe Martínez Lacalle, London, Tamesis.

ORDÓÑEZ, Alfonso.

Rojas, Fernando de (1506), Tragicocomedia di Calisto e Melibea nouamente traducta de spagnolo in italiano idioma [Alphonso Hordognez]. (Impressum Rome : in campo Flore per magistrum Eucharium Silber alias Franck, 1506 die uigesimanona Ianuarii). - [148] c. ; 4o. En Biblioteca Nacional Marciana de Venecia Dramm. 2988. 
Extraído de: Giraldo, Federica (2013), «Transcripción y estudio paleográfico de la primera traducción italiana de La Celestina (Bib. Marciana-DRAMM. 2988.5)", 798174-1172893.pdf. Tesis de licenciatura.

Versión no paleográfica en Kish, Kathleen (v. ref. bibliográfica en Bibliografía citada). 


\section{Calderón de la Barca Fernández, Víctor, «Mar y Mundo en el imaginario desiderativo de Melibea», Celestinesca 41 (2017), pp. 83-110.}

\section{RESUMEN}

La Celestina - Comedia y Tragicomedia - aparece mientras se suceden los viajes colombinos. La noticia del Descubrimiento no se limita a los centros de poder, también se pregona en las plazas de ciudades y pueblos. En este contexto se propone, yendo más allá del procedimiento retórico empleado, la hipótesis de que los sintagmas anfibológicos "rodear el mundo" y "pasar la mar» del parlamento de Melibea en el auto XVI puedan en su imaginario desiderativo referirse no al Mediterráneo, sino al Atlántico, y a una posible circunnavegación del globo terráqueo teóricamente demostrada, aunque aun no realizada. La lectura de la Celestina debe hacerse teniendo en cuenta el proyecto imperial de los Reyes Católicos y la reconceptualización de la imago mundi, a la que no podía ser ajeno un bachiller en Leyes de la universidad de Salamanca.

PALABRAS ClAVE: Pasar la mar y Rodear el mundo (Anfibologías) / El Atlántico en el imaginario desiderativo de Melibea / La Celestina en el contexto de los viajes colombinos.

\section{ABSTRACT}

The Celestina - both Comedy and Tragicomedy- appears while Columbus' voyages were taking place. News of the Discovery were not limited to the circles of power. They were also proclaimed in the squares of cities and villages. In this context, and going beyond the applied rhetorical procedure, this paper defends the hypothesis that the amphibological phrases "rodear el mundo" and "pasar la mar» pronounced by Melibea in the 16th auto, in her desiderative imagery, may well refer not to the Mediterranean Sea, but to the Atlantic Ocean, as well as to a possible circumnavigation of the Earth which, although not yet accomplished, had already been theoretically demonstrated.

KEY WORDS: Pasar la mar and Rodear el mundo (amphibologies) / The Atlantic Ocean in Melibea's desiderative imagery / The Celestina in the context of Columbus' voyages.

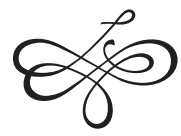

